\title{
MAIT cells reside in the female genital mucosa and are biased towards IL-17 and IL-22 production in response to bacterial stimulation
}

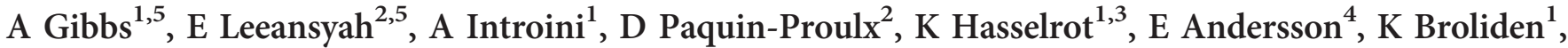 \\ JK Sandberg ${ }^{2}$ and A Tjernlund ${ }^{1}$
}

The female genital tract (FGT) mucosa is a critically important site for immune defense against microbes. Mucosalassociated invariant T (MAIT) cells are an innate-like T-cell population that recognizes microbial riboflavin metabolite antigens in an MR1-dependent manner. The role of MAIT cells in the FGT mucosa is unknown. Here, we found that MAIT cells and MR1 ${ }^{+}$antigen-presenting cells were present in the upper and lower FGT, with distinct tissue localization of MAIT cells in endometrium vs. cervix. The MAIT cells from the FGT and blood displayed a distinct phenotype with expression of interleukin (IL)-18R $\alpha, \mathrm{CD} 127, \alpha 4 \beta 7, \mathrm{PD}-1$, as well as the transcription factors promyelocytic leukemia zinc finger (PLZF), ROR $\gamma$ t, Helios, Eomes, and T-bet. Their expression levels of PLZF and Eomes were lower in the FGT compared with blood. When stimulated with Escherichia coli, MAIT cells from the FGT displayed a bias towards IL-17 and IL-22 expression, whereas blood MAIT cells produced primarily IFN- $\gamma$, TNF, and Granzyme B. Furthermore, both FGT- and blood-derived MAIT cells were polyfunctional and contributed to the T-cell-mediated response to E. coli. Thus, MAIT cells in the genital mucosa have a distinct IL-17/IL-22 profile and may have an important role in the immunological homeostasis and control of microbes at this site.

\section{INTRODUCTION}

The female genital tract (FGT) comprises different compartments with unique anatomical and immunological features, which all serve two main tasks: protection against invading pathogens and maintenance of a favorable environment for fertilization. ${ }^{1}$ The mucosa of the FGT provides an extraordinary barrier composed of an epithelium covered by mucus, and harbors numerous effector cells belonging to the innate and adaptive arms of the immune system. ${ }^{2}$ The mucosa of the uterus (endometrium) and the canal connecting the uterus and vagina (endocervix) are lined by a monolayer of columnar epithelial cells, and undergo major structural and functional changes during the menstrual cycle. ${ }^{2}$ The portion of the uterus facing the vaginal lumen (ectocervix) and the vagina display a thick squamous epithelium. Between the endocervix and ectocervix, where the epithelium transforms from single- to multilayered, lays the transformation zone that is characterized by a remarkable abundance of immune cells compared with the rest of the FGT. ${ }^{2,3}$

Although the mechanisms regulating immune responses in the FGT are not fully understood, the combined defenses of the genital mucosa effectively shield the host from pathogenic microbes as demonstrated, for instance, by the low efficiency of vaginal HIV-1 transmission. ${ }^{4}$ To this purpose, immediate immune responses at the site of microbial infection are mediated by cellular and soluble innate factors, which constitute a first line of defense and have a major role in shaping local adaptive immune responses. ${ }^{1,5,6}$

Mucosal-associated invariant T (MAIT) cells are a recently described innate T-cell population, which is abundant in the

\footnotetext{
${ }^{1}$ Unit of Infectious Diseases, Department of Medicine Solna, Center for Molecular Medicine, Karolinska Institutet, Karolinska University Hospital Solna, Stockholm, Sweden. ${ }^{2}$ Center for Infectious Medicine, Department of Medicine Huddinge, Karolinska Institutet, Karolinska University Hospital Huddinge, Stockholm, Sweden. ${ }^{3}$ Department of Obstetrics and Gynecology, Danderyd Hospital, Stockholm, Sweden and ${ }^{4}$ Department of Clinical Pathology/Cytology, Capio St Göran Hospital, Stockholm, Sweden. Correspondence: A Tjernlund (annelie.tjernlund@ki.se)

${ }^{5}$ These authors contributed equally to this work.
} 
mucosal tissues, blood, and liver. ${ }^{7-9}$ The MAIT cells express a semi-invariant T-cell receptor, including V $\alpha 7.2$ coupled with restricted $J \alpha$ segments $(J \alpha 33, J \alpha 12$, or $J \alpha 20)$, and limited $V \beta$ repertoires. ${ }^{10,11}$ The human MAIT cells are defined by the surface expression of their semi-invariant $\mathrm{T}$-cell receptor in combination with the high expression of the C-type lectin CD161 and the interleukin (IL)-18 receptor $\alpha$-subunit (IL-18R $\alpha)^{9}{ }^{9,12}$ The mature MAIT cells display an effector memory phenotype and exhibit a distinct transcriptional profile, expressing promyelocytic leukemia zinc finger (PLZF) and retinoic acid-related orphan receptor $\gamma \mathrm{t}(\mathrm{ROR} \gamma \mathrm{t})$ transcription factors. ${ }^{8,9}$ The MAIT cells also express classical effector $\mathrm{T}$ cell T-box transcription factors T-bet and Eomesodermin (Eomes) as well as Helios, a transcription factor involved in T-cell activation and proliferation. ${ }^{13-15}$ Decreased expression of these transcription factors in chronic HIV-1 infection is associated with MAIT-cell depletion in circulation and functional impairment of MAIT cells following bacterial stimulation. ${ }^{13}$ The MAIT cells recognize microbial vitamin B2 metabolites presented via the evolutionarily conserved major histocompatibility complex (MHC) class I-related (MR) 1 molecule. ${ }^{7,12,16,17}$ Upon activation, these cells have the capacity to produce cytokines such as interferon (IFN) $\gamma$, tumor necrosis factor (TNF), IL-17, and IL-22, suggesting their involvement in both antimicrobial responses and preservation of mucosal barrier integrity. ${ }^{8,12,18}$ Furthermore, the MAIT cells have been shown to be associated with protection against mycobacterial infections in both mice and humans. ${ }^{12,19,20}$

Despite the growing body of research on MAIT cells in humans, their presence in the FGT has not yet been investigated. In the current study, we characterized the localization and phenotype of MAIT cells in the mucosa from different compartments of the FGT in healthy women and compared them with circulating MAIT cells. Using an ex vivo model of bacterial stimulation with Escherichia coli (E. coli), we analyzed the functionality of MAIT cells by measuring the production of selected cytokines and effector proteins relevant to antimicrobial responses and mucosal homeostasis. We found that MAIT cells reside in the mucosa throughout the FGT, are biased towards IL-17 and IL-22 expression, and may thus contribute to antimicrobial immune defenses at this site. Our data point to MAIT cells as an active component of the early immune defenses of the FGT and serve as the basis for further investigation of their role in women's health and disease.

\section{RESULTS \\ Clinical data and $\mathrm{CD}^{+}{ }^{+}$and $\mathrm{CD} 8^{+} \mathrm{T}$-cell counts in the study populations}

Study participants $(n=38$, median age 49 years, range $35-62$ years) were recruited at the St Göran Hospital Gynecological Clinic where they were admitted to undergo hysterectomy due to benign conditions. Before the surgery, a physician interviewed all the patients and they were all found to have good general health. Individuals who were seropositive for HPV (human papilloma virus), reported symptoms or clinical signs of sexually transmitted infections at the time of surgery or during 3 months before surgery, or were treated with corticosteroids or other systemic immunosuppressive therapy were excluded from the study.

Thirty-five women were premenopausal and three were postmenopausal. Neither age nor menstrual status affected the downstream immunological comparisons performed between the study participants (data not shown). Detailed characteristics of the women donating genital tissue are included in Supplementary Table 1 online. Peripheral blood samples were collected from healthy women $(n=16)$ who were in the same age range as the women who underwent hysterectomy (median age 46 years, range 30-60 years). Individuals using immunosuppressive drugs were not eligible as blood donors. Frequencies of $\mathrm{CD} 4^{+}$and $\mathrm{CD} 8{ }^{+} \mathrm{T}$ cells in the endometrium, cervix, and blood were determined by flow cytometry, and $\mathrm{CD}^{+}{ }^{+}$and $\mathrm{CD} 8{ }^{+} \mathrm{T}$ cells were defined as $\mathrm{CD} 45^{+} \mathrm{CD} 3{ }^{+} \mathrm{CD} 4{ }^{+}$ cells and $\mathrm{CD} 45^{+} \mathrm{CD}^{+}{ }^{+} \mathrm{CD} 8{ }^{+}$cells, respectively. The $\mathrm{CD} 4 /$ CD8 ratio in the endometrium and cervix was 0.96 and 1.07 , respectively, whereas it was 2.15 in blood. These results are in agreement with previous reports on the distribution of $\mathrm{CD} 4^{+}$ and $\mathrm{CD} 8{ }^{+} \mathrm{T}$ cells in cervicovaginal mucosal tissue. ${ }^{21}$

\section{MAIT cells and MR1 ${ }^{+}$antigen-presenting cells reside in the upper and lower FGT}

In situ staining was used to determine the localization and distribution of MAIT cells in mucosal specimens from different portions of the FGT, including the endometrium, endocervix, transformation zone, and ectocervix. The MAIT cells were defined by immunofluorescent double-staining for $\mathrm{V} \alpha 7.2$ in combination with IL-18R $\alpha$, which were co-expressed on all $\mathrm{CD} 161^{\text {high }} \mathrm{V} \alpha 7.2^{+} \mathrm{T}$ cells, a phenotype identifying MAIT cells, isolated from the cervix and endometrium as evaluated by flow cytometry (Supplementary Figure 1). The MAIT cells were present throughout the FGT; however they displayed a diverse distribution within the analyzed compartments. The scattered MAIT cells were located in close proximity to and within the glandular epithelium in the lamina propria of the endometrium (Figure 1a). The endocervical MAIT cells were primarily localized adjacent to the simple columnar epithelium (Figure 1b), while in the transformation zone, MAIT cells were primarily found in the lamina propria (Figure 1c). Furthermore, ectocervical MAIT cells were located on both sides of the basal membrane, with the majority residing within clusters of IL-18R $\alpha^{+}$cells in the epithelium (Figure 1d). Moreover, in situ double staining of $\mathrm{V} \alpha 7.2$ and $\mathrm{CD} 3$, as well as of $\mathrm{CD} 3$ and $\mathrm{CD} 8$, in consecutive tissue sections confirmed that the $\mathrm{V} \alpha 7.2^{+}$cells within the FGT were T cells and localized in proximity to other $\mathrm{T}$ cells (Supplementary Figure 2). Additional double staining of $\mathrm{V} \alpha 7.2$ and CD8 showed that $\mathrm{V} \alpha 7.2^{+}$cells were also $\mathrm{CD}^{+}$(data not shown).

We next investigated whether $\mathrm{MR}^{+}{ }^{+}$antigen-presenting cells (APCs) were present within the same sites as MAIT cells. Thus, consecutive tissue sections of the endometrium and ectocervix were stained for MAIT cells and MR1 ${ }^{+}$APCs, which were defined by co-expression of MR1 and the APC marker HLA-DR. Similar to MAIT cells, MR1 ${ }^{+} \mathrm{HLA}^{-\mathrm{DR}^{+}}{ }^{+}$cells were 

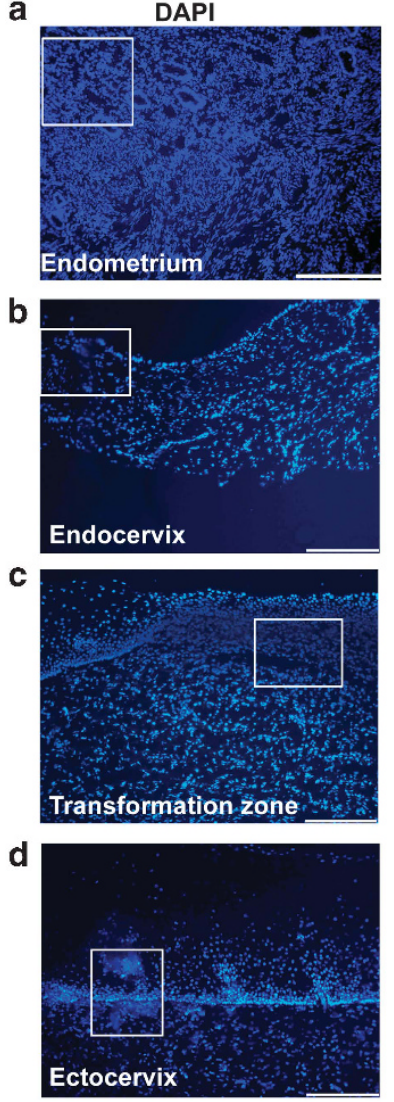

$V_{\alpha} 7.2$
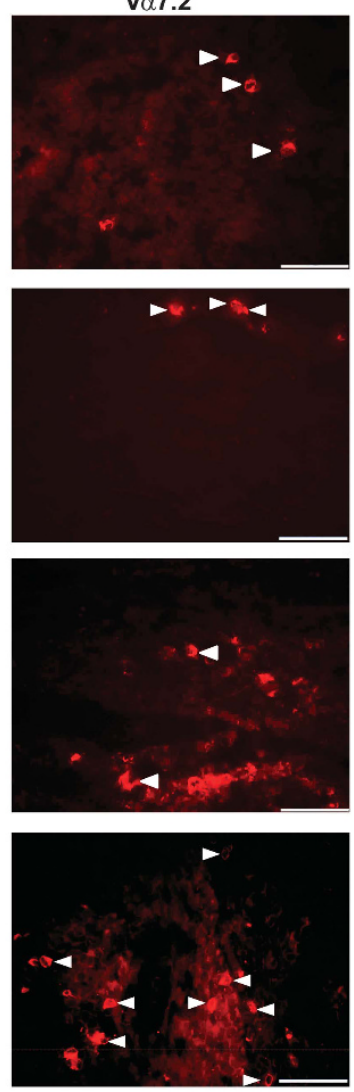

IL-18R $\alpha$
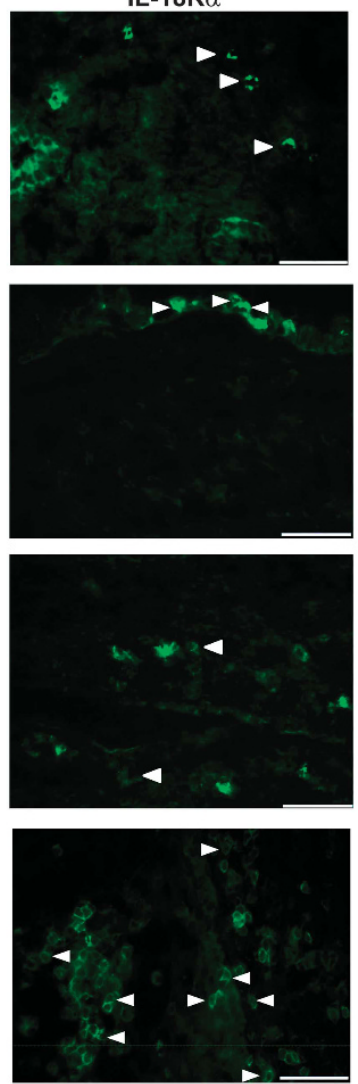
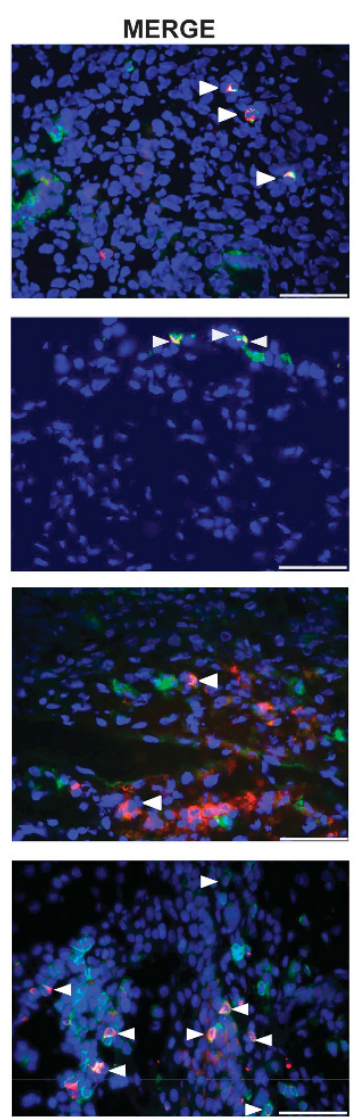

Figure 1 Localization and spatial distribution of MAIT cells in the FGT. Representative immunofluorescence images of $(a)$ endometrial $(n=6)$, (b) endocervical $(n=2)$, (c) transformation zone $(n=2)$, and (d) ectocervical $(n=6)$ tissue sections stained for $\mathrm{V} \alpha 7.2^{+}(\mathrm{red})$ and IL-18R $\alpha^{+}(\mathrm{green})$ cells. To be noted, the $40 \times$ pictures of the ectocervix were rotated $90^{\circ}$ right from the $10 \times$ overview picture. DAPI (blue) was used as a counterstain for the visualization of cell nuclei. Double-positive (MAIT) cells are shown in yellow and are indicated by the white arrows. The images were collected with $10 \times$ and $40 \times$ objectives. The scale bars are $250 \mu \mathrm{m}$ in the images in the first column and $60 \mu \mathrm{m}$ in the images in the other three columns. DAPI, 4',6-diamidino2-phenylindole; FGT, female genital tract; MAIT, mucosal-associated invariant T.

located within or in close proximity to the glandular epithelium of the endometrium and on both sides of the basal membrane in the ectocervix (Figure 2a). We also characterized the distribution of different APC subsets as well as their expression of MR1 in endometrial and ectocervical tissue samples. In line with previous observations, ${ }^{22,23}$ we found that Langerin ${ }^{+}$cells were a minor population in endometrium, while they were more common in the ectocervix. The $\mathrm{CD} 11 \mathrm{c}^{+}$dendritic cells were abundant in both compartments (data not shown). Furthermore, MR1 was expressed on $\mathrm{CD} 11 \mathrm{c}^{+}$cells in both the endometrium and ectocervix as well as on a few Langerin ${ }^{+}$cells in the epithelial compartment of the ectocervix (Figure 2b).

\section{Comparable numbers and CD8/CD4 distribution of MAIT cells in FGT and blood}

Next, flow cytometry was used to enumerate MAIT cells and assess their phenotype in the endometrium, cervix, and blood samples. Due to the limited endocervix samples available, the endocervix and ectocervix were combined for this analysis and referred to as cervix. The MAIT cells were identified as $\mathrm{CD} 45^{+} \mathrm{CD} 3{ }^{+} \mathrm{CD} 161^{\text {hi }}$ V $\alpha 7.2^{+}$cells (Figure 3a). The MAIT cells isolated from the endometrium and cervix were quantified in comparable amounts (Figure $\mathbf{3 b}$ ), and accounted for 1 and $1.8 \%$, respectively, of the T-cell population, defined as $\mathrm{CD} 45^{+}$ $\mathrm{CD}^{+}$cells. In blood, MAIT cells represented about $2.1 \%$ of T cells, thus accounting for a significantly higher proportion of cells compared with the endometrium $(P=0.01)$, but not the cervix (Figure $3 \mathbf{b}$ ). The MAIT cells preferentially express CD8 with minor populations being $\mathrm{CD}^{+}$or double negative $\left(\mathrm{CD} 4^{-} \mathrm{CD} 8^{-}\right)$. There were significant differences between these three subpopulations in the endometrium $(P<0.0001)$, cervix $(P=0.006)$ and blood $(P<0.0001)$. Specifically, the percentage of $\mathrm{CD}^{+}$MAIT cells among $\mathrm{T}$ cells was significantly higher compared with both $\mathrm{CD} 4^{+}$MAIT cells and $\mathrm{CD} 4{ }^{-} \mathrm{CD} 8^{-}$MAIT cells in all the three compartments analyzed: in the endometrium, $\mathrm{CD} 8{ }^{+} \mathrm{CD} 4^{-}, \mathrm{CD} 8{ }^{-} \mathrm{CD} 4^{+}$, and $\mathrm{CD}^{-}{ }^{-} \mathrm{CD}^{-}$MAIT cells were 69,12 , and $11 \%$ $(P<0.0001)$; in the cervix 75,13 , and $12 \%(P=0.008)$; and in blood 84,2 , and $8 \%(P<0.0001)$, respectively. Furthermore, in blood, $\mathrm{CD} 4{ }^{+}$MAIT cells were significantly lower compared with $\mathrm{CD} 8{ }^{-} \mathrm{CD} 4{ }^{-}$MAIT cells (2 vs. $8 \%, P=0.02$ ) (Figure $3 \mathbf{b}$ ). In addition, similar frequencies of these three subpopulations of MAIT cells were observed between the different compartments, except for blood $\mathrm{CD} 4{ }^{+}$MAIT cells, which were significantly 

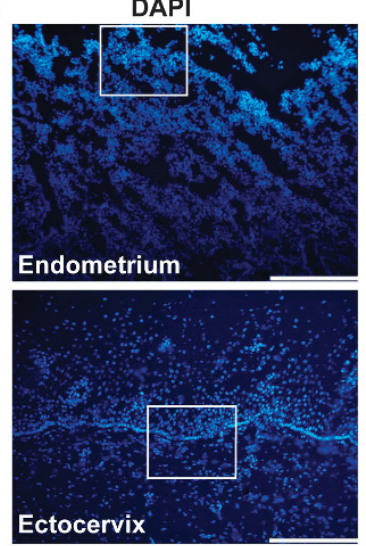

b

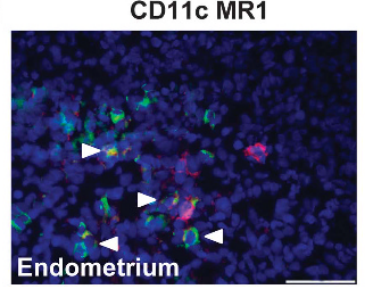

MR1
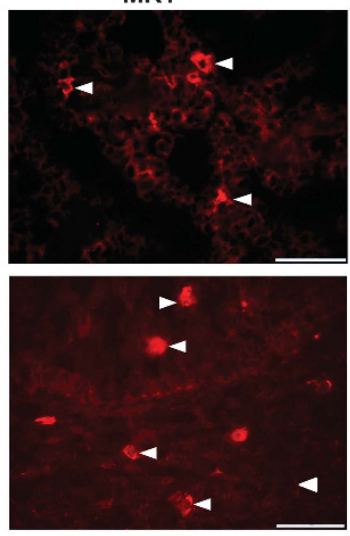

CD11c MR1

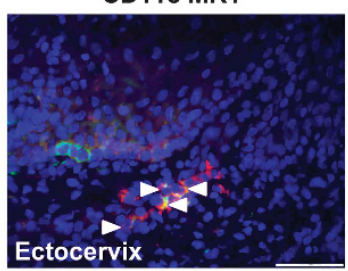

HLA-DR
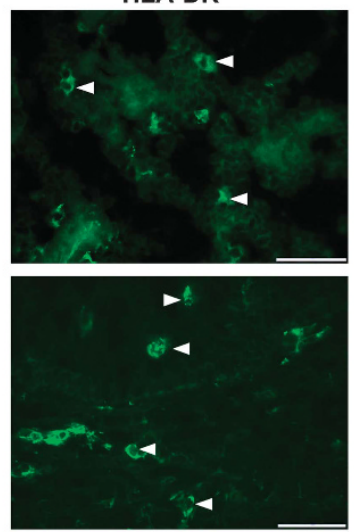

Langerin MR1

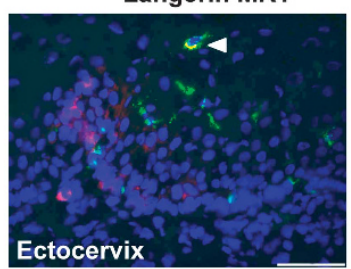

Figure 2 Localization and spatial distribution of MR1 ${ }^{+}$APCs in the endometrium and ectocervix. Representative immunofluorescence images of endometrial $(n=2)$ and ectocervical $(n=2)$ tissue sections stained for (a) MR1 (red) and HLA-DR (green); the scale bars are $250 \mu \mathrm{m}$ in the images in the first column and $60 \mu \mathrm{m}$ in the images in the other three columns. (b) Representative immunofluorescence images of endometrial and ectocervical tissue sections stained for MR1 (red) with CD11c (green) and MR1 (red) with Langerin (green); scale bar = $60 \mu \mathrm{m}$. Double-positive cells are shown in yellow and are indicated by the white arrows. DAPI (blue) was used as a counterstain for visualization of cell nuclei. The images were collected with $10 \times$ and $40 \times$ objectives. APC, antigen-presenting cell; DAPI, 4',6-diamidino-2-phenylindole.

a
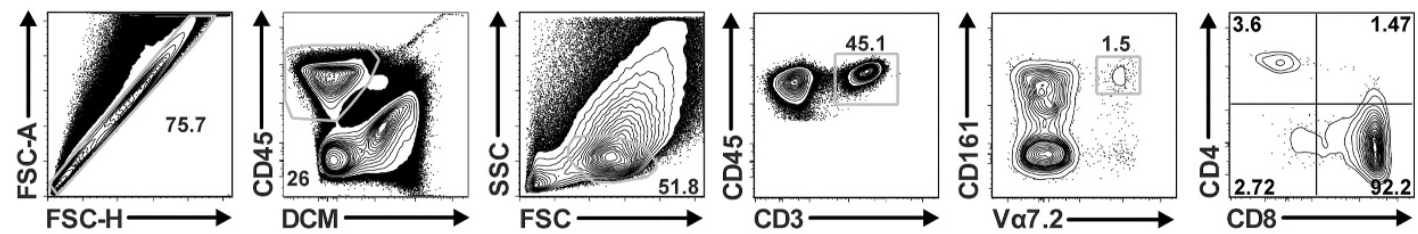

b

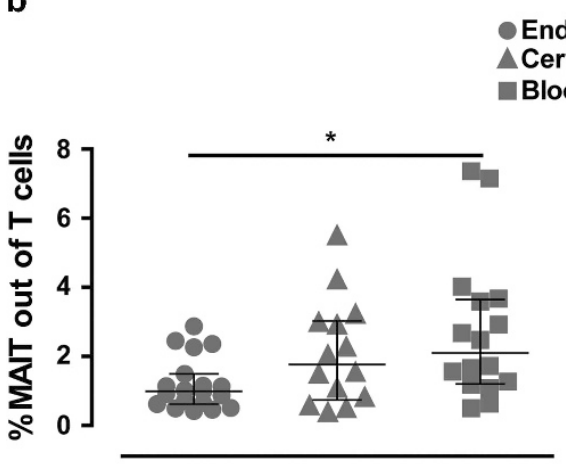

C

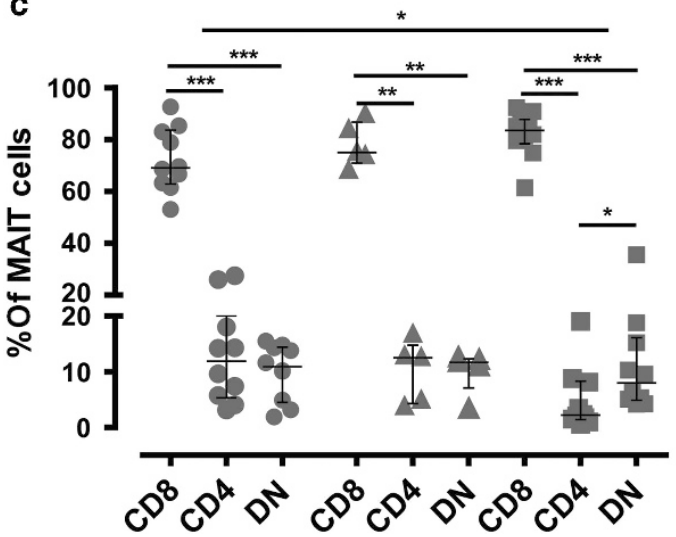

Figure 3 Enumeration of the frequency of MAIT cells in the FGT and blood. (a) MAIT cell (CD161 $\left.1^{\text {high }} \mathrm{V} \alpha 7.2^{+}\right)$gating strategy and representative scatter plots. (b) Frequencies of MAIT cells out of T cells $\left(\mathrm{CD} 45^{+} \mathrm{CD} 3^{+}\right)$from the endometrium $(n=19)$, cervix $(n=14)$, and blood $(n=16)$. (c) Frequencies of CD8 $\left(\mathrm{CD} 4^{-} \mathrm{CD} 8^{+}\right), \mathrm{CD} 4\left(\mathrm{CD} 4^{+} \mathrm{CD}^{-}\right)$, and DN $\left(\mathrm{CD} 4^{-} \mathrm{CD} 8^{-}\right)$MAIT cells out of total MAIT cells from the endometrium $(n=10)$, cervix $(n=5)$, and blood $(n=10)$. The cervix samples consisted of pooled endocervical and ectocervical cells. Each dot represents a different patient; endometrium (circle), cervix (triangle), and blood (square). Horizontal lines represent median \pm interquartile range. ${ }^{\star} P<0.05,{ }^{* \star} P<0.01$, ${ }^{\star * \star} P<0.001$. FGT, female genital tract; MAIT, mucosal-associated invariant T. 
lower compared with endometrial $\mathrm{CD} 4{ }^{+}$MAIT cells (2 vs. $12 \%, P=0.01$ ) (Figure 3b).

\section{Distinct transcription factor profiles of MAIT cells in the FGT and blood}

We next characterized the expression of IL-18R $\alpha$, IL-7 receptor- $\alpha$ chain (CD127), the mucosal homing integrin $\alpha 4 \beta 7$, and PD-1, which are expressed on MAIT cells from blood, liver, and other mucosal tissues. ${ }^{8,18,24-26}$ The MAIT cells from the endometrium, cervix, and blood displayed a universal expression of these markers, which was distinct from conventional $\mathrm{CD} 8{ }^{+}$and $\mathrm{CD} 4^{+} \mathrm{T}$ cells (Supplementary Figure 1b).

We further characterized the transcription factor expression profile of endometrial, cervical, and blood MAIT cells. Similar expression levels of PLZF, ROR $\gamma \mathrm{t}$, Helios, Eomes, and T-bet were observed between MAIT cells from the endometrium and cervix. However, endometrial MAIT cells and cervical MAIT cells, in comparison with those in blood, showed significantly lower expression levels of PZLF (median GMFI: 121 vs. 156; $P=0.01$ ) and Eomes (median GMFI: 776 vs. $1689 ; P=0.01$ ), respectively (Figure 4a). Despite these differences, the overall expression pattern of the transcription factors in MAIT cells was similar between the three compartments and distinct from conventional T cells (Figure 4b) (Supplementary Figure 3).

\section{MAIT cells in the FGT are biased towards IL-17 and IL-22 production upon E. coli stimulation}

We next investigated the activation and cytokine production of MAIT cells from the FGT and blood in responses to bacteria encoding the riboflavin biosynthesis pathway. The endometrial and cervical samples were pooled to achieve a sufficient yield of cells needed for stimulation experiments, and these cells were referred to as FGT cells. The stimulation of cells from the FGT and blood with E. coli, or with PMA (phorbol 12-myristate 13acetate), triggered production of IFN- $\gamma$, TNF, IL-17A (further referred to IL-17), IL-22, and GrzB in MAIT cells (Figure 5a). To increase the sensitivity of our bacterial stimulation assay, CD28 co-stimulation was included; however, this did not alter the response profiles of MAIT cells (Supplementary Figure 4a). In addition, stimulation with $E$. coli in the presence of MR1-blocking antibody resulted in a reduction of MAIT cell production of IFN- $\gamma$, TNF, and IL-17, indicating that the in vitro stimulation of MAIT cells occurred through bacterial antigen presentation on MR1 molecules. Notably, the production of IL-22 and GrzB by MAIT cells was not altered by the MR1-blocking antibody (Supplementary Figure $4 \mathrm{~b}$ ).

On average, E. coli stimulation induced IL-17 and IL-22 in a significantly higher fraction of MAIT cells from the FGT than in blood ( 9 vs. $1 \% ; P=0.0005$ and 2 vs. $0.2 \% ; P=0.04$, respectively). In contrast, the production of IFN- $\gamma$, TNF, and GrzB in response to E. coli was lower in FGT-derived MAIT cells compared with blood (IFN- $\gamma 10$ vs. $65 \% ; P=0.004$, TNF 11 vs. $38 \% ; P=0.008$, and GrzB 41 vs. $87 \% ; P=0.003$; Figure 5b).

We next investigated whether the preferential IL-17 and IL-22 production upon E. coli stimulation in the FGT was restricted to MAIT cells. We found that the total IL-17 and IL-22 production by $\mathrm{CD} 45^{+}$lymphocytes was two-fold and 20 -fold higher in the FGT compared with blood, whereas in contrast, $\mathrm{CD} 45^{+}$lymphocytes in the FGT produced lower levels of IFN- $\gamma$ and TNF compared with blood (Supplementary Figure 5a). We further assessed the production of these cytokines by $\mathrm{CD}_{3}{ }^{-} \mathrm{CD} 45^{+}$(non-T cells) and $\mathrm{CD} 3{ }^{+} \mathrm{CD} 45^{+}$ (T cells) cells in the FGT and blood and, as expected, these cells had a different cytokine expression profile, depending on their anatomical origin (Supplementary Figure 5b). Furthermore, in line with previous findings showing that Th17 cells are a major subset in the $\mathrm{FGT},{ }^{27}$ we found that the frequencies of both IL-17 and IL-22 producing CD4 ${ }^{+} \mathrm{T}$ cells were significantly elevated in the FGT compared with blood (Supplementary Figure 5c). Collectively, these data indicate that MAIT cells as well as other immune cells within the FGT are more prone to produce IL-17 and IL-22 after E. coli stimulation.

\section{MAIT cells in the FGT have a distinct polyfunctional profile} on $E$. coli stimulation

We further assessed the, E. coli induced, polyfunctional profile of MAIT cells from the FGT and blood, using the SPICE software. The majority of MAIT cells in the FGT were monofunctional cells (68.6\%), with lower frequencies of bi- and trifunctional cells (17.5 and 13.3\%, respectively). In contrast, the circulating MAIT cells had similar proportions of monoand bifunctional cells ( 43.5 and $38.9 \%$, respectively), and a lower frequency of trifunctional cells (17.1\%). For both the sites, the frequency of tetra- and penta-functional MAIT cells were low, although the FGT appeared to have slightly higher proportions of these highly polyfunctional cells ( 2.4 vs. $0.5 \%$, respectively) (Figure 6a). The polyfunctional profile of MAIT cells (i.e., cells exhibiting $>1$ function) from the FGT was different from that observed in blood. Specifically, the frequencies of $\mathrm{GrzB}^{+} \mathrm{IL}-17^{+}$MAIT cells were significantly elevated in the FGT compared with blood $(P=0.01)$, while significantly lower frequencies of MAIT cells in the FGT comprised bifunctional $\mathrm{GrzB}^{+} \mathrm{IFN} \gamma^{+}(P<0.0001)$ and $\mathrm{GrzB}^{+}$ $\mathrm{TNF}^{+}(P=0.02)$ cells. Likewise, similar observations were noted for the trifunctional MAIT cells, with significantly higher proportion of $\mathrm{GrzB}^{+} \mathrm{IFN}-\gamma^{+} \mathrm{IL}-17^{+}$and $\mathrm{GrzB}^{+} \mathrm{IL}-17^{+}$ $\mathrm{TNF}^{+}$cells in the FGT vs. blood $(P=0.05$ and $P=0.05$ respectively), and significantly lower proportion of $\mathrm{GrzB}^{+}$ IFN $\gamma^{+} \mathrm{TNF}^{+}$as well as $\mathrm{GrzB}^{+} \mathrm{IL}^{-22}{ }^{+} \mathrm{TNF}^{+}$cells in the FGT vs. blood ( $P=0.005$ and $P=0.004$, respectively; Figure $6 \mathbf{b}$ ). Noteworthy, while monofunctional $\mathrm{GrzB}^{+}$MAIT cells were present in both the compartments, single-producing $\mathrm{IL}-17^{+}$ MAIT cells $(P=0.0009)$ and co-producing $\mathrm{IL}-17^{+} \mathrm{IL}-22^{+}$ MAIT cells were more common in the FGT (Figure $6 \mathbf{b}$ ).

\section{DISCUSSION}

This is the first study to show that MAIT cells, as well as MR1 ${ }^{+}$ APCs, are present in the upper and lower FGT of healthy women. The MAIT cells displayed a scattered distribution throughout the FGT, except for the ectocervix where the majority localized within clusters of IL- $18 \mathrm{R} \alpha^{+}$cells in the 
a
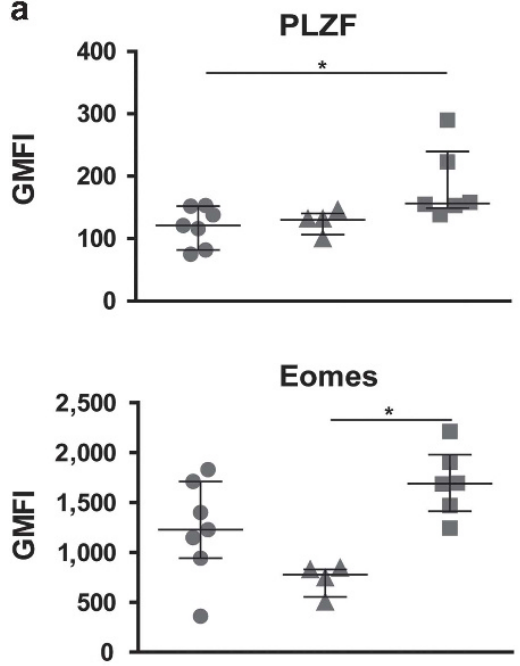

RORyt

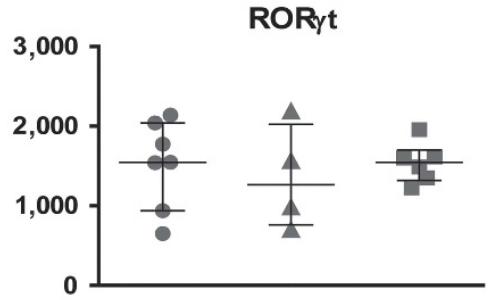

T-bet

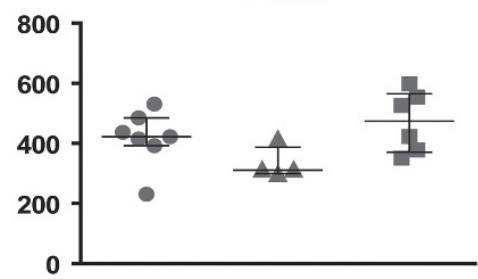

Helios

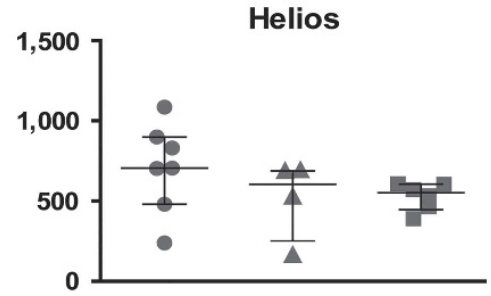

b
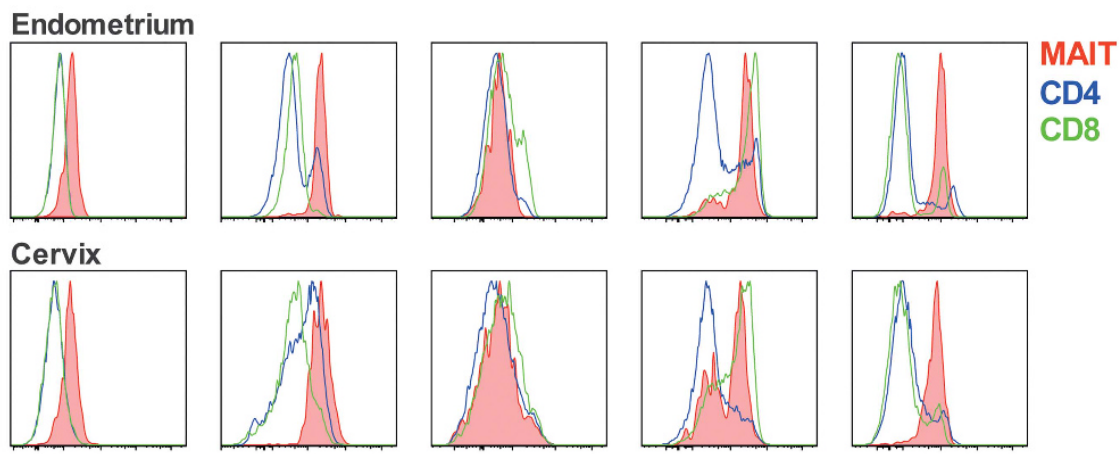

Blood
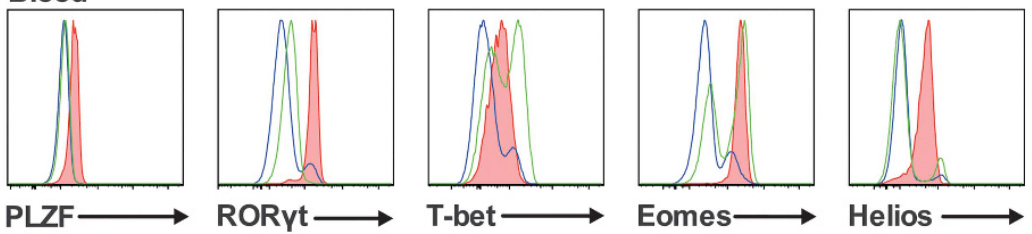

Figure 4 Expression of transcription factors in MAIT cells in the FGT and blood. Expression levels of PLZF, ROR $\gamma$ t, Helios, Eomes, and T-bet transcription factors in MAIT cells (GMFI, geometric mean intensity fluorescence). (a) Scatter plots represent the expression levels of transcription factors in MAIT cells from the endometrium $(n=7)$, cervix $(n=4)$, and blood $(n=6)$. Each symbol represents a different patient; endometrium (circle), cervix (triangle), and blood (square). Horizontal lines represent the median \pm interquartile range, ${ }^{*} P<0.05$. (b) Representative histograms showing the expression levels of transcription factors in MAIT cells (red), CD4 ${ }^{+}$T cells (blue), and CD8 ${ }^{+}$T cells (green) from the endometrium $(n=7)$, cervix $(n=4)$, and blood $(n=6)$. FGT, female genital tract; MAIT, mucosal-associated invariant T; PLZF, promyelocytic leukemia zinc finger.

epithelium. As the upper FGT is considered to be a relatively "sterile" milieu compared with the lower FGT, 1,2 the preferential localization of MAIT cells in the ectocervical epithelium may serve a functional purpose by sensing potential pathogenic microbes and the commensal microbiota populating the cervicovaginal environment. For instance, the Lactobacillus species, which belong to the commensal flora of the FGT, have stimulatory effects on murine MAIT cells. ${ }^{12,28,29}$ As activation of MAIT cells is primarily MR1-dependent, ${ }^{7,12,16}$ we also investigated the presence of MR1 ${ }^{+}$APCs in the FGT. MR1 was expressed on dendritic cells that were localized at the same anatomical sites as MAIT cells within the FGT, thus indicating that MAIT cells and $\mathrm{MR} 1^{+}$APC have the potential to interact.
The MAIT cells in the FGT and in blood displayed similar frequency and a shared phenotype with expression of IL-18R $\alpha$, CD127, PD-1, and $\alpha 4 \beta 7$, and comparable CD4/CD8 distribution. Furthermore, in both the anatomical sites, the MAIT cells displayed a transcription factor profile with expression of PLZF, ROR $\gamma$ t, Helios, Eomes, and T-bet, distinct from conventional $\mathrm{CD}^{+}{ }^{+}$and $\mathrm{CD}^{+}{ }^{+} \mathrm{T}$ cells. These observations indicate that MAIT cells residing in the genital mucosa display an effector memory-like phenotype and thus have the capacity to act as a first line of defense against invading microbial pathogens. Interestingly, PLZF and Eomes expression was lower in MAIT cells from the FGT as compared with blood, indicating that the transcriptional profile may differ to some extent between the circulating and mucosal MAIT cells. 
a
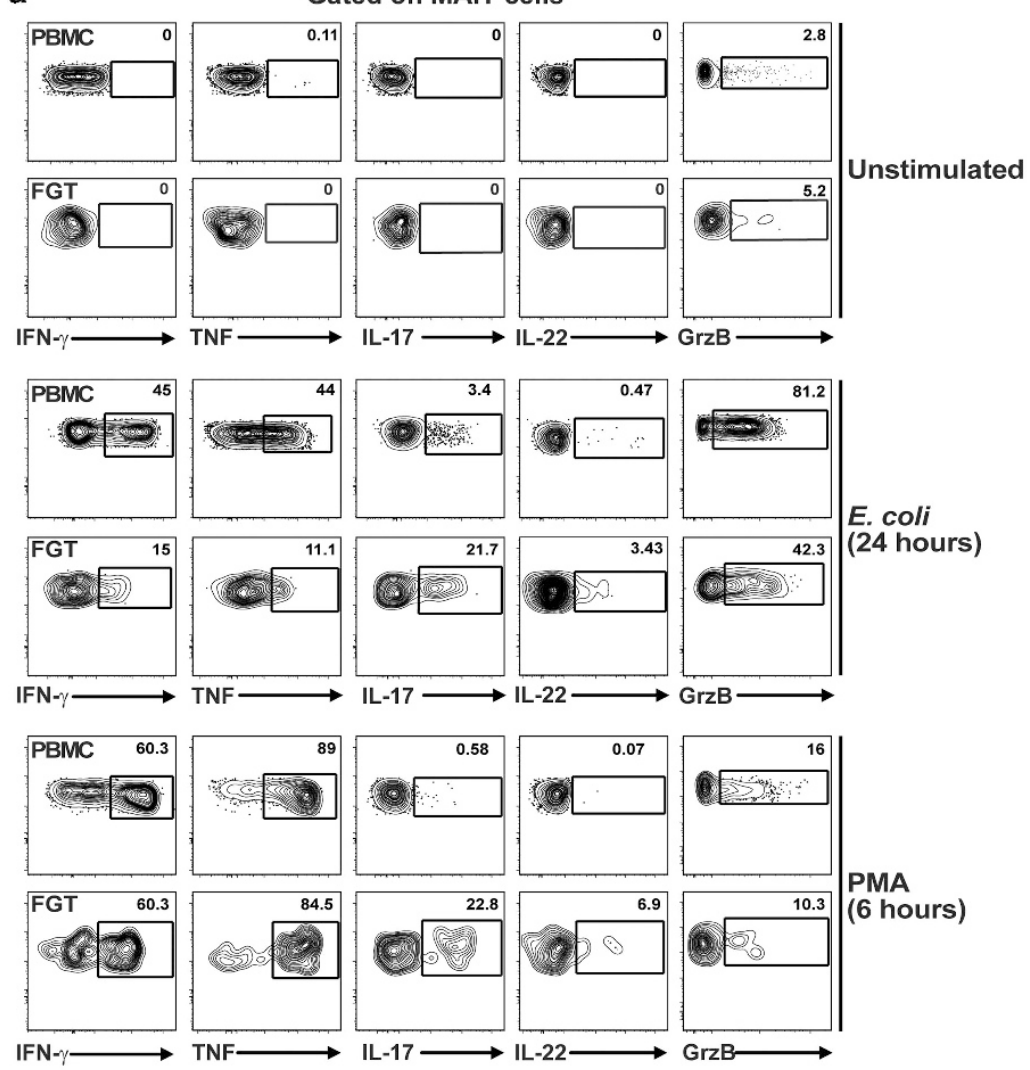

24 hours)
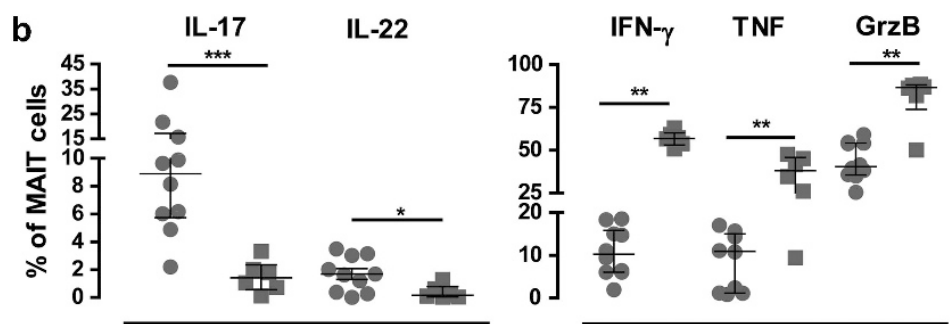

- FGT

Blood

Figure 5 Cytokine and GrzB production profile by MAIT cells in the FGT and blood upon E. coli stimulation. (a) Representative dot plot showing IFN- $\gamma$, TNF, IL-17, IL-22, and GrzB production by MAIT cells from FGT and blood samples that were either unstimulated (upper panel; $n=8$ ), stimulated with E.coli (middle panel; FGT $n=10$, blood $n=6$ ), or stimulated with PMA (lower panel; $n=4$ ). (b) Frequencies of cytokines and GrzB production by MAIT cells from the FGT $(n=10)$ and blood $(n=6)$. Each symbol represents a different patient; FGT (circle) and blood (square). Horizontal lines represent median \pm interquartile range. ${ }^{\star} P<0.05$, ${ }^{\star \star} P<0.01,{ }^{* \star \star} P<0.001$. FGT, female genital tract; IFN, interferon; IL, interleukin; MAIT, mucosal-associated invariant T; TNF, tumor necrosis factor; PBMC, peripheral blood mononuclear cell; PMA, phorbol 12-myristate 13-acetate.

To investigate the potential role of MAIT cells in the mucosal defense against microbes, we characterized the cytokine profile of FGT- and blood-derived MAIT cells in response to E. coli stimulation. Mildly fixed E. coli was used as an ex vivo model of bacterial stimulation. E. coli is not part of the normal commensal genital microflora in healthy women and is the most common gram-negative pathogen causing anaerobic vaginitis. The prevalence of diagnosed symptomatic anaerobic vaginitis varies from 5 to $10 \%$ in non-pregnant women. ${ }^{30}$ Here we showed that although E. coli-stimulated MAIT cells from both the compartments were capable of producing GrzB, IFN- $\gamma$, TNF, IL-17, and IL-22, the FGT-derived MAIT cells were more prone to produce IL-17 and IL-22, whereas blood MAIT cells preferentially produced IFN $-\gamma$, TNF, and GrzB. The preferential IL-17 and IL-22 production in the genital mucosa was not limited to MAIT cells as the other immune cells within the FGT also produced these cytokines, highlighting that the FGT environment is more predisposed for production of these cytokines.

Our stimulation data were additionally validated by assessing E. coli-induced activation of MAIT cells in the presence of an MR1-blocking antibody, which significantly reduced the production of IFN- $\gamma$, TNF, and IL-17. Notably, we observed that expression levels of GrzB and IL-22 were not sensitive to MR1 blocking. This is in agreement with previous studies showing that GrzB production by MAIT cells is highly sensitive to the influence of a range of innate, inflammatory, and homeostatic cytokines, including IL-7, IL-12, IL-15, and 
a
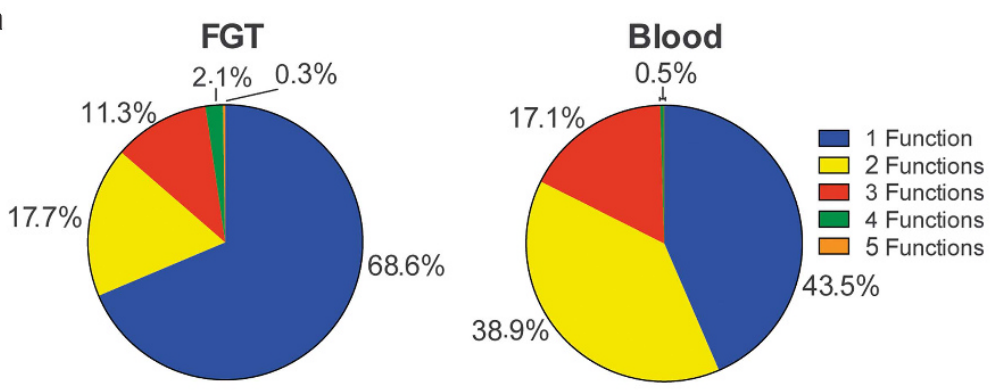

b

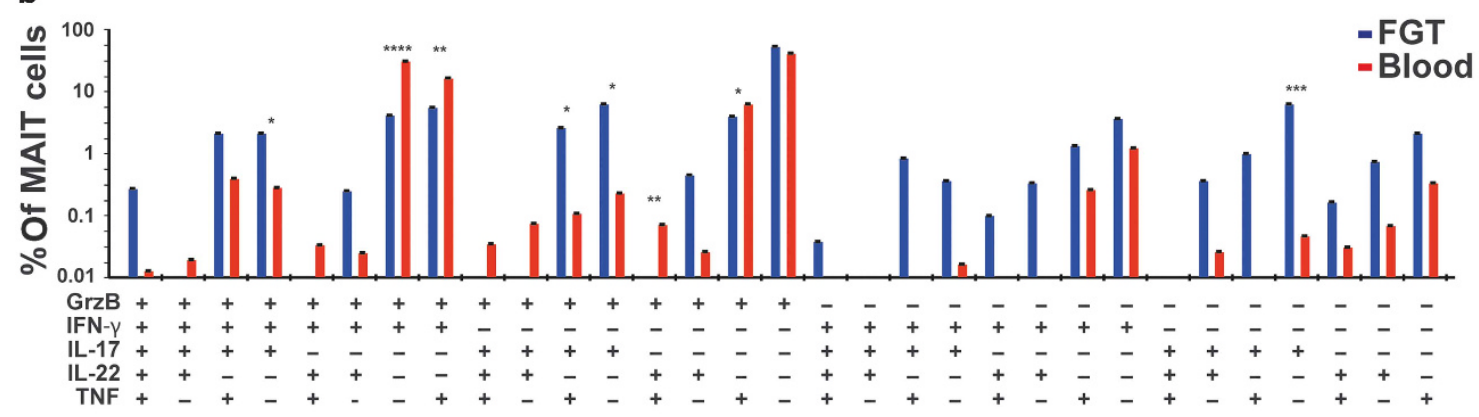

1Function
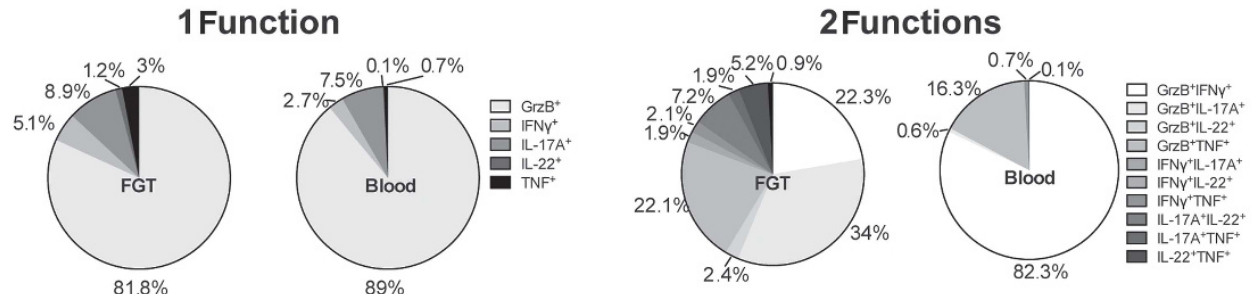

3Functions
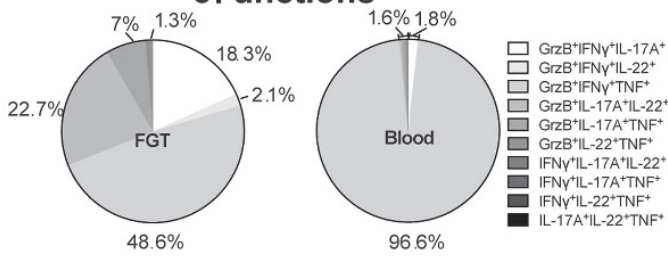

Figure 6 Polyfunctional characterization of MAIT cells from the FGT $(n=10)$ and blood $(n=6)$, using SPICE software. (a) Left and right pie charts representing the number of functions expressed by MAIT cells from the FGT and blood, respectively (b) Bar and pie charts showing the distribution of GrzB, IFN- $\gamma$, IL-17, IL-22 and TNF combinations expressed by MAIT cells from the FGT (blue) and blood (red). Permutation test was performed between the bar charts. ${ }^{*} P<0.05,{ }^{* \star} P<0.01,{ }^{* \star \star} P<0.001,{ }^{* \star *} P<0.0001$. FGT, female genital tract; IFN, interferon; IL, interleukin; MAIT, mucosal-associated invariant $\mathrm{T}$; TNF, tumor necrosis factor.

IL-18 in an antigen-independent and MR1-independent manner. ${ }^{13,31-33}$ This may possibly also be applicable to MAIT cell IL-22 production, but it requires further investigation.

Deeper analyses of the E. coli induced cytokine profile of MAIT cells revealed that they displayed distinct polyfunctional profiles depending on their anatomical origin. The FGTderived MAIT cells displayed a mixed Th1/Th17 phenotype, with co-expression of Th1 effector molecules and IL-17, and to a lesser extent IL-22. In contrast, the circulating MAIT cells predominantly co-expressed GrzB, IFN $\gamma$, and TNF. We also observed a relatively large GrzB single-producing MAIT cell population, which may possibly represent a subset of MAIT cells that produce cytokines other than those examined in this study. Our data thus reveal that FGT-derived MAIT cells respond to bacterial stimuli in a manner that is unique to the FGT, supporting their importance as early immune mediators of immune responses on infection of the FGT.

This difference in cytokine production and polyfunctionality is intriguing, considering that IL-17 and IL-22 have a pivotal role in mucosal immune responses. ${ }^{34,35}$ IL-17 is crucial for expression of antimicrobial peptides and antifungal defenses in skin and mucosal tissues, and IL-22 is also involved in regulation of the mucosal barrier integrity by promoting epithelial cell proliferation and epithelial tight junction protein expression in the mucosal tissues. ${ }^{34-37}$ In addition, IL-17 and IL-22 levels are increased in genital secretions of women with various genital infections, including trichomonas, chlamydia, and gonorrhea; however the source of these cytokines in the 
FGT remains unclear. ${ }^{38-40}$ The MAIT cells are located close to the lumen of the FGT and can thus possibly serve as sentinels for incoming pathogens. It would hence be interesting to further investigate whether Chlamydia and Neisseria gonorrhoeae could stimulate cytokine production by MAIT cells, in a similar manner as shown here for E. coli. Furthermore, IL- $1 \beta$ and IL- 6 that are known to be important for IL-17 and IL-22 responses, are present in secretions from the upper and lower FGT and are significantly upregulated during genital infections locally, but not systemically. ${ }^{40-42}$ Owing to the limitations in sample availability, these cytokines were not measured here. However, IL- $1 \beta$ and IL- 6 have been shown to be higher in genital secretions compared with blood in healthy premenopausal women. ${ }^{43}$ Thus, one may speculate that the preferential IL-17 and IL-22 production by MAIT cells in the FGT may be modulated by the local microflora and cytokine environment.

The difference in functional profile between MAIT cells in the FGT and blood may also be influenced by differences in the transcriptional profile of these cells. A recent study by Rahimpour et al. showed that murine MAIT cells displayed functional plasticity associated with ROR $\gamma \mathrm{t}$ and T-bet expression levels resulting in either preferential IL-17 or IFN- $\gamma$ production. ${ }^{44}$ Our data showed that FGT-derived MAIT cells displayed lower Eomes and PLZF expression than MAIT cells from blood. However, since the transcription factor profile of MAIT cells was assessed in unstimulated samples, owing to limited sample availability, it is difficult to ascertain the role in driving the preferential functional phenotypes of MAIT cells in the FGT.

A potential caveat in this study is that FGT and blood samples were not derived from the same donors. However, all the study subjects were healthy women within the same age range and none used immunosuppressive drugs. Another limitation of working with tissue biopsies obtained from the human FGT is the limited sample availability. In addition, although it would have been preferable to distinguish the response to E. coli between the upper and lower FGT, this was not feasible due to the relatively low numbers of MAIT cells retrieved. Furthermore, sex hormones affect the FGT and the immune cell distribution within the mucosa. ${ }^{2}$ Novak et al. ${ }^{45}$ reported higher numbers of MAIT cells in blood from women who were of reproductive age (15-50 years of age) compared with age-matched men, suggesting that sex hormones may influence the number of MAIT cells in blood. Although we did not observe any differences in the frequency of MAIT cells between pre- and postmenopausal women, the impact of sex hormones on the MAIT cells should be further investigated.

In summary, this is the first study to show that MAIT cells, as well as MR1 ${ }^{+}$APCs, are localized near the luminal surface of the genital mucosa of healthy women. The combination of MAIT cell localization in the mucosa and their capacity to rapidly produce cytokines suggests that they may be an important component of the first line of defense against invading pathogens. In virtue of their polyfunctionality as well as preferential IL-17 and IL-22 production compared with their circulating counterparts, mucosal MAIT cells together with other innate immunity components and the local microflora, may also act as keepers of mucosal homeostasis and barrier integrity. The present study provides a foundation for future studies of mucosal MAIT cells in acute and chronic genital infections, which will ultimately lead to a better understanding of the mechanisms regulating immunity in the FGT.

\section{METHODS}

Study population and sample collection. Uterine tissue samples were obtained from 38 Swedish women who underwent hysterectomy for nonmalignant and noninflammatory conditions such as heavy menstrual bleeding or benign myoma at the St Göran Hospital in Stockholm, Sweden. HPV infection was diagnosed with the PapilloCheck HPV genotyping test (Greiner Bio-One $\mathrm{GmbH}$, Kremsmünster, Austria) by the accredited microbiological laboratory service at the Karolinska University Hospital in Stockholm, Sweden. Peripheral blood samples were collected from healthy Swedish women in the same age range as women who underwent a hysterectomy, and were recruited at the Blood Transfusion Clinic at the Karolinska University Hospital in Stockholm, Sweden. Written informed consent was obtained from all the donors and ethical approval was obtained from the Regional Ethical Review Board of Stockholm.

Processing of uterus specimens and peripheral blood mononuclear cells. The samples of endometrium and cervical mucosa were collected by a pathologist immediately after the hysterectomy. The amount of tissue obtained varied depending on the overall dimension of the surgical specimens. At least $1 \mathrm{~cm}^{2}$ of mucosa (approximately $500 \mathrm{mg}$ wet weight) was required for downstream applications. Samples were maintained in ice-cold RPMI 1640 supplemented with $50 \mu \mathrm{g} \mathrm{ml}^{-1}$ of gentamicin and $2.5 \mu \mathrm{g} \mathrm{ml}^{-1}$ of Fungizone (Gibco, Life Technologies Europe BV, Stockholm, Sweden), and processed within $24 \mathrm{~h}$ of surgery. For each specimen, the mucosa was separated from any residual underlying stromal or muscular tissue and dissected into approximately $8 \mathrm{~mm}^{3}$ blocks using a scalpel and tweezers, as previously described. ${ }^{46}$ One or two tissue blocks were snap-frozen immediately after dissection and cryopreserved at $-80^{\circ} \mathrm{C}$ for in situ staining. The remaining tissue blocks were digested with $0.1 \mathrm{mg} \mathrm{ml}^{-1}$ of DNase I (Roche, Basel, Switzerland) and $0.5 \mathrm{mg} \mathrm{ml}^{-1}$ of Collagenase II (Sigma Aldrich, St Louis, MO) in a thermoshaker (Labnet International, Edison, NJ) rocking at 1,400 r.p.m. for $30 \mathrm{~min}$ at $37^{\circ} \mathrm{C}$. The digested tissue blocks were mechanically disrupted with a pestle. The obtained cell suspension was filtered through a $70-\mu \mathrm{m}$ cell strainer (BD Biosciences, San Jose, CA) and washed in phosphate-buffered saline by centrifugation at $400 \mathrm{~g}$ for $5 \mathrm{~min}$. For flow cytometry, mononuclear cells were isolated by density gradient centrifugation at $900 \mathrm{~g}$ for $20 \mathrm{~min}$ using Ficoll-Hypaque (Axis-Shield, Dundee, Scotland). Peripheral blood mononuclear cells were isolated by FicollHypaque density gradient centrifugation and either allowed to rest overnight in complete medium before use in the functional assay (see below) or cryopreserved in liquid nitrogen until required for the phenotypic analysis (see below).

In situ fluorescence staining. In situ staining was performed on 8 - $\mu \mathrm{m}$-thick sections of the cryopreserved tissue samples. The tissue sections were fixed in $2 \%$ formaldehyde for $10 \mathrm{~min}$ and then washed with phosphate-buffered saline. Immunofluorescent double-staining of $V \alpha 7.2$ and IL-18 $R \alpha ; V \alpha 7.2$ and CD3; V $\alpha 7.2$ and CD8; CD3 and CD8 as well as of MR1 and HLA-DR, MR1 and CD11c; MR1 and Langerin were done sequentially. The following monoclonal primary antibodies were used: mouse antihuman V $\alpha 7.2$ antibody (clone 3C10, BioLegend, San Diego, CA); goat antihuman IL-18R $\alpha$ antibody (AF840, R\&D Systems, Minneapolis, MN); rabbit antihuman CD3 antibody (clone SP7, Abcam, Cambridge, UK); Alexa 488 conjugated mouse antihuman CD8 antibody (clone RPA-T8, BD Biosciences); mouse 
antihuman MR1 antibody (clone 8F2.F9, ${ }^{47}$ a kind gift from Dr Ted Hansen); biotinylated mouse antihuman HLA-DR antibody (clone L243, BD Biosciences) that was used in combination with streptavidinconjugated Alexa Fluor 488 (Molecular Probes, Life Technologies Europe BV, Stockholm, Sweden); FITC conjugated mouse antihuman CD11c (clone B-ly6, BD Biosciences); and rat antihuman Langerin (clone 929F3.01, Dendritics, Lyon, France). The following secondary antibodies were used: Alexa Fluor 594 or 488-conjugated donkey antimouse IgG antibody; Alexa Fluor 488-conjugated donkey anti-goat IgG antibody; Alexa Fluor 488-conjugated donkey anti-rat IgG antibody; Alexa Fluor 594-conjugated donkey anti-rabbit IgG antibody (Molecular Probes, Life Technologies Europe BV). The tissue sections were mounted with Vectashield containing DAPI (4',6-diamidino-2-phenylindole; Vector Laboratories, Burlingame, CA). The negative controls were included and consisted of incubations in the presence of secondary antibody alone. The images were acquired on a DMR-X microscope (Leica, Wetzlar, Germany) with a Retiga 2000R camera (QImaging, Surrey, Canada). The acquired images were processed using Image-Pro Premier 9.1 software (Media Cybernetics, Rockville, MD).

Flow cytometry. The cell surface staining was performed using directly conjugated antibodies and the cells were fixed in Cytofix/ Cytoperm or in transcription factor fixation/permeabilization buffer (both from BD Biosciences) as appropriate. Intracellular staining was performed in Perm/Wash or Transcription Factor Perm/Wash buffer as appropriate (both from BD Biosciences). The samples were acquired on an LSRFortessa flow cytometer (BD Biosciences) equipped with $405,488,561$, and $639 \mathrm{~nm}$ lasers. Single-stained polystyrene beads (BD Biosciences) were used for compensation purposes. Software-based compensation was performed using the compensation platform in FlowJo software version 9.6 (Tree Star, Ashland, OR). Distribution of effector molecules expressed by the MAIT cells was compared using SPICE software version $5.35 .^{48}$ The antibodies used in the experiments are listed in Supplementary Table 2.

Functional assay. MAIT cell functions were determined in vitro using a formaldehyde-fixed E. coli stimulation (D21 strain, fixed in 1\% formaldehyde for 5 min multiplicity of infection $=5$ ) in the presence of $1.25 \mu \mathrm{g} \mathrm{ml}^{-1}$ anti-CD28 mAb (clone L293, BD Biosciences) and, in selected experiments, $20 \mu \mathrm{g} \mathrm{ml}^{-1}$ anti-MR1 mAb (clone 26.5; BioLegend) or IgG2 isotype control (clone MOPC-173, BioLegend). Peripheral blood mononuclear cells or FGT-derived mononuclear cells were further cultured for $24 \mathrm{~h}$ at $37^{\circ} \mathrm{C}$ and $5 \% \mathrm{CO}_{2}$ in RPMI medium supplemented with $10 \%$ fetal calf serum and $50 \mu \mathrm{g} \mathrm{ml}^{-1}$ gentamicin (Gibco). Monensin (Golgi Stop, BD Biosciences) was added during the last $6 \mathrm{~h}$ of the stimulation. The cells stimulated for $6 \mathrm{~h}$ with PMA/ionomycin (Leukocyte Activation Cocktail, BD Biosciences) and in the presence of monensin were included in parallel as positive controls.

Statistical analyses. Statistical significance between continuous variables was assessed using the Mann-Whitney $U$-test for comparisons of independent samples and the Wilcoxon signed rank test for paired samples. Furthermore, multiple comparison analysis were performed with the use of the Kruskal-Wallis test followed by Dunn's post hoc test for independent samples and the Friedman test followed by Dunn's post hoc test for paired samples. Prism 5.00 for Windows (GraphPad Software, San Diego, CA) was used for statistical analysis and a $P$ value $<0.05$ was considered significant. Permutation tests were analyzed using the data analysis program SPICE version $5.35 .{ }^{48}$

SUPPLEMENTARY MATERIAL is linked to the online version of the paper at http://www.nature.com/mi

\section{ACKNOWLEDGMENTS}

We thank all the study participants as well as Dr Flam, Dr Glaessgen, Dr Kaldensjö, and Dr Bradley for their assistance in collecting the cervical tissue samples. A.G. was supported by funds from the Karolinska
Instititutet's faculty funds. E.L. was supported by funds from the Clas Groschinsky Memorial Funds, the Swedish Institute Swedish Physicians against AIDS Foundation, and the Swedish Society for Medicine. A.I. was supported by the Blanceflor Boncompagni Ludovisi, née Bildt Foundation. K.B. was supported by the Swedish Research Council. J.K.S. was supported by the Swedish Cancer Society, the Petrus and Augusta Hedlund Foundation, the Swedish Research Council, and the US National Institutes of Health grant R01DK108350. A.T. was supported by grants from the Clas Groschinsky Memorial Funds, and the Swedish Society of Medicine.

\section{DISCLOSURE}

The authors declared no conflict of interest.

Official journal of the Society for Mucosal Immunology

\section{REFERENCES}

1. Quayle, A.J. The innate and early immune response to pathogen challenge in the female genital tract and the pivotal role of epithelial cells. J. Reprod. Immunol. 57, 61-79 (2002).

2. Wira, C.R., Rodriguez-Garcia, M. \& Patel, M.V. The role of sex hormones in immune protection of the female reproductive tract. Nat. Rev. Immunol. 15, 217-230 (2015).

3. Pudney, J., Quayle, A.J. \& Anderson, D.J. Immunological microenvironments in the human vagina and cervix: mediators of cellular immunity are concentrated in the cervical transformation zone. Biol. Reprod. 73, 1253-1263 (2005)

4. Boily, M.C. et al. Heterosexual risk of HIV-1 infection per sexual act: systematic review and meta-analysis of observational studies. Lancet Infect. Dis. 9, 118-129 (2009).

5. Burgener, A. et al. A systems biology examination of the human female genital tract shows compartmentalization of immune factor expression. J. Virol. 87, 5141-5150 (2013).

6. Valore, E.V., Park, C.H., Igreti, S.L. \& Ganz, T. Antimicrobial components of vaginal fluid. Am. J. Obstet. Gynecol. 187, 561-568 (2002).

7. Treiner, E. et al. Selection of evolutionarily conserved mucosal-associated invariant T cells by MR1. Nature 422, 164-169 (2003).

8. Dusseaux, M. et al. Human MAIT cells are xenobiotic-resistant, tissuetargeted, CD161 hi IL-17-secreting T cells. Blood 117, 1250-1259 (2011).

9. Martin, E. et al. Stepwise development of MAIT cells in mouse and human. PLoS Biol. 7, e54 (2009).

10. Reantragoon, R. et al. Antigen-loaded MR1 tetramers define Tcell receptor heterogeneity in mucosal-associated invariant T cells. J. Exp. Med. 210, 2305-2320 (2013).

11. Lepore, M. et al. Parallel T-cell cloning and deep sequencing of human MAIT cells reveal stable oligoclonal TCRbeta repertoire. Nat. Commun. 5, 3866 (2014).

12. Le Bourhis, L. et al. Antimicrobial activity of mucosal-associated invariant T cells. Nat. Immunol. 11, 701-708 (2010).

13. Leeansyah, E. et al. Arming of MAIT cell cytolytic antimicrobial activity is induced by IL-7 and defective in HIV-1 infection. PLOS Pathog. 11, e1005072 (2015).

14. Kaech, S.M. \& Cui, W. Transcriptional control of effector and memory CD8 + T cell differentiation. Nat. Rev. Immunol. 12, 749-761 (2012).

15. Akimova, T., Beier, U.H., Wang, L., Levine, M.H. \& Hancock, W.W. Helios expression is a marker of T cell activation and proliferation. PLoS One 6 , e24226 (2011).

16. Kjer-Nielsen, L. et al. MR1 presents microbial vitamin B metabolites to MAIT cells. Nature 491, 717-723 (2012).

17. Corbett, A.J. et al. T-cell activation by transitory neo-antigens derived from distinct microbial pathways. Nature 509, 361-365 (2014).

18. Leeansyah, E., Loh, L., Nixon, D.F. \& Sandberg, J.K. Acquisition of innatelike microbial reactivity in mucosal tissues during human fetal MAIT-cell development. Nat. Commun 5, 3143 (2014).

19. Sakala, I.G. et al. Functional heterogeneity and antimycobacterial effects of mouse mucosal-associated invariant $\mathrm{T}$ cells specific for riboflavin metabolites. J. Immunol. 195, 587-601 (2015).

20. Gold, M.C. et al. Human mucosal associated invariant T cells detect bacterially infected cells. PLoS Biol. 8, e1000407 (2010). 
21. Saba, E. et al. HIV-1 sexual transmission: early events of HIV-1 infection of human cervico-vaginal tissue in an optimized ex vivo model. Mucosal Immunol. 3, 280-290 (2010).

22. Kaldensjo, T. et al. Detection of intraepithelial and stromal Langerin and CCR5 positive cells in the human endometrium: potential targets for HIV infection. PLoS One 6, e21344 (2011).

23. Hirbod, T. et al. Abundant and superficial expression of C-type lectin receptors in ectocervix of women at risk of HIV infection. J. Acquir. Immune Defic. Syndr. 51, 239-247 (2009).

24. Carolan, E. et al. Altered distribution and increased IL-17 production by mucosal-associated invariant T cells in adult and childhood obesity. J. Immunol. 194, 5775-5780 (2015).

25. Hiejima, E. et al. Reduced numbers and proapoptotic features of mucosalassociated invariant $T$ cells as a characteristic finding in patients with inflammatory bowel disease. Inflamm. Bowel Dis. 21, 1529-1540 (2015).

26. Tang, X.Z. et al. IL-7 licenses activation of human liver intrasinusoidal mucosal-associated invariant T cells. J. Immunol. 190, 3142-3152 (2013).

27. Rodriguez-Garcia, M., Barr, F.D., Crist, S.G., Fahey, J.V. \& Wira, C.R. Phenotype and susceptibility to HIV infection of CD4 + Th17 cells in the human female reproductive tract. Mucosal Immunol. 7, 1375-1385 (2014).

28. Vasquez, A., Jakobsson, T., Ahrne, S., Forsum, U. \& Molin, G. Vaginal Lactobacillus Flora of healthy Swedish women. J. Clin. Microbiol. 40, 2746-2749 (2002).

29. Ravel, J. et al. Vaginal microbiome of reproductive-age women. Proc. Natl Acad. Sci. USA 108 (Suppl 1), 4680-4687 (2011).

30. Tansarli, G.S., Kostaras, E.K., Athanasiou, S. \& Falagas, M.E. Prevalence and treatment of aerobic vaginitis among non-pregnant women: evaluation of the evidence for an underestimated clinical entity. Eur. J. Clin. Microbiol. Infect. Dis. 32, 977-984 (2013).

31. Ussher, J.E. et al. CD161 + + CD8 + T cells, including the MAIT cell subset, are specifically activated by IL-12 + IL-18 in a TCR-independent manner. Eur. J. Immunol. 44, 195-203 (2014).

32. Kurioka, A. et al. MAIT cells are licensed through granzyme exchange to kill bacterially sensitized targets. Mucosal Immunol. 8, 429-440 (2015).

33. Sattler, A., Dang-Heine, C., Reinke, P. \& Babel, N. IL-15 dependent induction of IL-18 secretion as a feedback mechanism controlling human MAIT-cell effector functions. Eur. J. Immunol. 45, 2286-2298 (2015).

34. Sonnenberg, G.F., Fouser, L.A. \& Artis, D. Border patrol: regulation of immunity, inflammation and tissue homeostasis at barrier surfaces by IL22. Nat. Immunol. 12, 383-390 (2011).

35. Weaver, C.T., Elson, C.O., Fouser, L.A. \& Kolls, J.K. The Th17 pathway and inflammatory diseases of the intestines, lungs, and skin. Annu. Rev. Pathol. 8, 477-512 (2013).

36. Puel, A. et al. Inborn errors of human IL-17 immunity underlie chronic mucocutaneous candidiasis. Curr. Opin. Allergy Clin. Immunol. 12, 616622 (2012).

37. Kim, C.J. et al. A role for mucosal IL-22 production and Th22 cells in HIVassociated mucosal immunopathogenesis. Mucosal Immunol. 5, 670-680 (2012).
38. Makinde, H.M. et al. IL-22 levels are associated with Trichomonas vaginalis infection in the lower genital tract. Am. J. Reprod. Immunol. 70, 38-44 (2013).

39. Jha, R. et al. Spontaneous secretion of interleukin-17 and -22 by human cervical cells in Chlamydia trachomatis infection. Microbes Infect. 13, 167-178 (2011).

40. Masson, L. et al. Defining genital tract cytokine signatures of sexually transmitted infections and bacterial vaginosis in women at high risk of HIV infection: a cross-sectional study. Sex. Transm. Infect. 90, 580-587 (2014).

41. Zielinski, C.E. et al. Pathogen-induced human $\mathrm{TH} 17$ cells produce IFN-gamma or IL-10 and are regulated by IL-1beta. Nature 484, 514-518 (2012).

42. Boomsma, C.M. et al. Cytokine profiling in endometrial secretions: a noninvasive window on endometrial receptivity. Reprod. Biomed. Online 18, 85-94 (2009).

43. Al-Harthi, L. et al. The impact of the ovulatory cycle on cytokine production: evaluation of systemic, cervicovaginal, and salivary compartments. J. Interferon Cytokine Res. 20, 719-724 (2000).

44. Rahimpour, A. et al. Identification of phenotypically and functionally heterogeneous mouse mucosal-associated invariant T cells using MR1 tetramers. J. Exp. Med. 212, 1095-1108 (2015).

45. Novak, J., Dobrovolny, J., Novakova, L. \& Kozak, T. The decrease in number and change in phenotype of mucosal-associated invariant T cells in the elderly and differences in men and women of reproductive age. Scand. J. Immunol. 80, 271-275 (2014).

46. Introini, A., Vanpouille, C., Grivel, J.C. \& Margolis, L. An ex vivo model of HIV-1 infection in human lymphoid tissue and cervico-vaginal tissue. Bio. Protoc. 4, e1047 (2014).

47. Chua, W.J. et al. Endogenous MHC-related protein 1 is transiently expressed on the plasma membrane in a conformation that activates mucosal-associated invariant T cells. J. Immunol. 186, 4744-4750 (2011).

48. Roederer, M., Nozzi, J.L. \& Nason, M.C. SPICE: exploration and analysis of post-cytometric complex multivariate datasets. Cytometry A 79, 167-174 (2011).

(a) (1) () This work is licensed under a Creative Commons (a) Attribution-NonCommercial-NoDerivs 4.0 International License. The images or other third party material in this article are included in the article's Creative Commons license, unless indicated otherwise in the credit line; if the material is not included under the Creative Commons license, users will need to obtain permission from the license holder to reproduce the material. To view a copy of this license, visit http://creativecommons.org/licenses/by-nc-nd/4.0/ 